\title{
Correspondence
}

\section{A survey on attitudes towards job-sharing among psychiatric trainees \\ DeAr Sirs}

The issue of part-time postgraduate training in medicine is not new. However, there are times in the history of some issues when the whisper of concerned voices becomes gradually more and more voluble. It was within the context of the growing undercurrent of interest (as well as recognition of the statistical evidence of medical school outputs approaching a 50:50 sex ratio) that the St George's Women in Psychiatry Group decided to carry out an attitude survey towards job-sharing among psychiatric trainees.

The results of polling the registrars (total number of replies 29/40) and senior registrars (total number of replies 12/20) on the psychiatric training rotations at St George's Hospital in July 1986 showed that $54 \%$ of female respondents and $68 \%$ of male respondents expressed very few or no theoretical problems with splitting their post at the time of questioning for the purposes of job-sharing. Only $3 / 16$ women and $2 / 25$ men felt that the possibility of splitting their post was very small or impossible. The attitudes to job-sharing were also interesting, in that many respondents (14/15 females and $9 / 25$ males) identified a possible or definite desire for part-time work at sometime in their future career.

Several respondents felt that job-sharing should be available at all levels of training, including at consultant level. Most respondents were in favour of job-sharing schemes in general, others felt that this would be an imperfect solution to a more general problem of excessively long work hours with lack of flexibility, and felt that a broader approach needed to be taken to this problem in the form of improving doctors' working conditions and reducing work load.

In a comments section of our questionnaire we noted that apart from the common reason given for the need for part-time training, i.e. that of family/domestic commitments, several respondents, mostly men, expressed the wish for time to pursue other activities, such as personal therapy, psychotherapy training, creative hobbies and other unspecified interests. Also approximately a third of male respondents stated their intentions to be closely involved in family commitments to the extent of wishing that the option of job-sharing existed. One male registrar commented on his experience of being the son of a female doctor, stating that job-sharing should be more widely available. Other comments focused on the fact that job-sharing would increase the number of doctors in employment, would decrease the wastefulness of training a proportion of women doctors only to be lost to medical practice, and that a better service could be achieved by the combination of two doctors, particularly if they had a variety of skills to offer. The additional experiential value of a psychiatrist who had been closely involved in the upbringing of her/his children was however the most important benefit seen arising from part-time work.

There were also a number of anxieties expressed in the questionnaire. These included the difficulty of finding a co-sharer with similar training interests at compatible level, the importance of careful handover and cover for absences between job-sharers, the danger of part-time workers working more than their allotted time and the extended duration of training as a consequence of job-sharing. Other important practical problems mentioned were the need for the health service to provide adequate childcare facilities, to protect part-timers from spending excessive time and money on childcare arrangement, and that in practical terms' job-sharing was only open to women.

Clearly the issue of job-sharing is only one aspect of the greater debate surrounding the post-graduate training and medical manpower questions. Our survey suggests that there is a further issue being raised: that of doctors' involvement in other major commitments (particularly family commitments) apart from work, for both male and female doctors. We feel that the need for adequate alternatives to full-time training will escalate, particularly at the senior registrar level. The present supernumary scheme is too ad hoc and bureaucratic to continue satisfactorily in its present form as this need increases. The time is ripe for reviewing the assumptions underlying present job-structure available, both in terms of manpower efficiency and the satisfaction of trainees.

\section{MARIE THERESE ATTARD} JenNy STILES

St George's Hospital, London SWI7

\section{Consultants and administrators}

\section{Dear Sirs}

I would like to applaud Ian Macllwain's letter in the August 1986 issue (Bulletin, 10, 211-212) entitled 'Consultants and Administrators', in which he draws a parallel between pathology in that relationship and some marital situations. He describes the controlling, insensitive husband (administrator) who increasingly seeks to infantilise (manage) the irresponsible, emotive wife (clinician), who in turn increasingly criticises and undermines (clinical autonomy) the administrator. It is as if two people are leaning further and further out, on opposite sides of a dinghy, in order to steady the (already steady) boat, each feeling the need to counter-balance the perceived extremes of the other in order to maintain the status quo. This vicious circle is, of course, potentially a 'game without end' in which the clinical and administrative functions of the NHS remain split and conflicting.

However, this analysis, and its attendant prescription for "each party to become aware of their contributions to the 
deteriorating relationship" is too narrow. Firstly, there are additional important roles in the scenario: other people who can shift their own weight in the boat. Secondly, the context is of an increasingly financially constrained, centralised and authoritarian society, in which only the more exploitative aspects of individualism are fostered: a blustery gale in a choppy sea indeed.

The NHS is not composed solely of consultants and administrators; indeed it may be fruitful for a moment to cast other staff in the role of (more or less) dependent or individuated children. On this model, sibling rivalry between other professions for power, status, hegemony, etc., is being contained and acted out in the consultant versus administrator battle. Perhaps we shall see disputes in the 'lower ranks' involving clinical and administrative issues, which may then help the consultants and administrators either to pull together within the NHS, or finally separate (private practice).

The wider context, too, will also inevitably change. While financial constraints look set to tighten, it is by no means certain that the current emphasis on the economics of service delivery will continue to take precedence indefinitely over a medical notion which seeks to maximise the relief of individual suffering regardless of cost.

To add to Ian's prescription I would, in the mode of family rather than marital therapy, suggest that consultants and administrators could fruitfully get together to compare notes on the differences between the various pressures and constraints under which they respectively operate, and hope also that other staff will see fit to helpfully 'rock the boat'.

Department of Child and Family Psychiatry

Medway Health Authority, Chatham

Peter Hollis

\section{Old case notes}

DEAR SIRS

I wrote recently to a colleague at a particular clinic, asking him if I could borrow the notes of a child whom I had seen there when I was working in that clinic, whose younger brother had been referred to me.

I learnt to my consternation that a policy decision had been made by the clinic to destroy files on all patients when they reached the age of 25 years unless there were special reasons to retain them. The file I requested has, therefore, been destroyed.

I think this policy is an extremely unwise one. Many children with psychiatric problems grow up to have psychiatric problems as adults. It is of immense help to adult psychiatrists if they are able to consult the files of their patients when they were children. Furthermore, it vitiates any possibility of longitudinal research being done on these patients. Although the present staff of the clinic may not wish to do research, I think consideration should be given to enable those who come after to undertake this work. For example, a valuable piece of research has been done by Dr Zeitlin, ${ }^{1}$ who has linked up the patients seen as children at the Maudsley with their attendance as adults at the Maudsley and has furthered our understanding of the history of psychiatric disorder.

I understand that for reasons of space such a decision was made, but surely alternatives could be considered, such as micro-filming, rather than a wholesale destruction of vital and important clinical material.

\section{ReFERENCE}

'Zertun, H. (1986) The Natural History of Psychiatric Disorder in Children. Maudsley Monograph No. 29. London: Oxford University Press.

\section{DeAR SIRS}

I have been sent a copy of the letter complaining about our policy to destroy the old files of our patients (after they are 25) unless there are special reasons to retain them. In that letter there is a sentence: 'Although the present staff of the clinic may not wish to do research..... This is offensive, and, as such, unacceptable; maybe we are interested in other kinds of research.

Also, her consternation would have been less if she had known that a circular was sent by the Department of Health and Social Security to Regional Health AuthoritiesHC(80)7 May 1980-paragraph 5b-recommending a minimum retention period of the records for children and young people until the patient's 25 th birthday or eight years after the last entry if longer. It is what we do and, I suspect, many other agencies. The reason is the obvious one, the need for space.

However, I cannot disagree with the fact that sometimes it could be useful to have access to old files. But the alternatives suggested, like micro-filming, can be extremely expensive, and we must wonder if, in a time of expenditure cuts, a better use could not be found for the required amount of money.

(Names and addresses supplied)

\section{The dilemma of adolescent psychiatrists}

\section{DeAr SIRS}

My colleague, Tony Harbott, has v.ritten (Bulletin, January 1987, 11, 25)-perhaps more in sorrow than in anger-to reproach me for my views on the selection of disturbed adolescents for treatment (Cut Price Adolescent Units That Meet All Needs and None? Bulletin, September 1986, 10, 231-232).

The point of my paper was to emphasise the dilemma faced by all adolescent psychiatrists-if it is accepted that it is unreasonable to treat all categories in one unit, who should be excluded and what are the alternatives? In the past, most of us were taught that the treatment of conduct disorders, particularly those exhibiting personality disorder, is not really a medical responsibility, and that as a group they are not sufficiently responsive to treatment to 